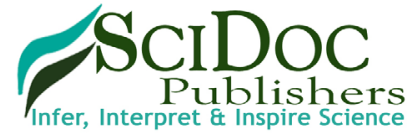

\title{
Anaesthesia Considerations and Management In Case of First Trimester Heterotopic Pregnancy Undergoing a Laparoscopic Ectopic Excision
}

\author{
Case Report
}

\section{Sukriti D. Atram ${ }^{1}$, Sushant P. Bhabal $2^{*}$}

${ }^{1}$ Associate Professor at Department of Anaesthesia and critical care, Grant Government Medical college and Sir J.J. Group of hospitals, Mumbai, Maharashtra, India.

${ }^{2}$ Junior Resident at Department of Anaesthesia and critical care, Grant Government Medical college and Sir J.J. Group of Hospitals, Mumbai, Maharashtra, India.

\section{Abstract}

Heterotopic pregnancy is a presence of intrauterine and extra-uterine gestation concurrently. It might be rare but possess great challenge for an anaesthetist as both maternal and foetal safety are at risk. We report a case of 28 years primigravida diagnosed as heterotopic pregnancy and shifted for an emergency laparoscopic ectopic excision under General anaesthesia. Our primary concern for maternal and foetal safety for undergoing surgery in first trimester pregnancy was achieved by Meticulous attention to preoperative counselling, airway management, aspiration prophylaxis, haemodynamic stability, choice of anaesthesia and anaesthetic drugs which have minimal impact on utero-placental perfusion and uterine relaxation. On follow up the patient delivered a healthy full term live female child weighing $2.7 \mathrm{~kg}$ by elective cesarean section.

Keywords: Heterotopic Pregnancy; Maternal Safety; Live Gestation; First Trimester.

\section{Introduction}

The incidence of heterotopic pregnancy is estimated to be $1 / 30,000$ in spontaneous pregnancy but more recent data indicate that the rate is higher due to assisted reproduction and is approximately 1 in 7000 overall and as high as 1 in 900 with ovulation induction $[1,2]$. This rare obstetric condition carries considerable maternal morbidity and mortality, also the surgical intervention exposes both the mother and the foetus to the risks of anaesthesia. In such cases we are not only concerned about the safety of mother but also conserving the Intrauterine pregnancy.

\section{Case Report}

We report a case of 28 years Primigravida married since 1.5 years came with 6 weeks of amenorrhea with an ultrasound report suggestive of heterotopic pregnancy showing a well-defined Intrauterine Gestation sac of 5 weeks 3 days and extra-uterine gestation sac of 4 weeks which was present in the left fallopian tube. Patient had no history of infertility or use of any assisted reproductive technologies; she had no risk factors for an ectopic pregnancy. Patient had no complaints of pain in abdomen or per vaginal bleeding, any leakage of fluids, urinary symptoms, fever, dizziness, palpitations or any comorbid conditions.

On examination the patient was vitally stable. All routine investigations showed Haemoglobin $11.2 \mathrm{gm} / \mathrm{dl}$; white blood cells $11,300 / \mathrm{cmm}$ Platelets $282000 / \mathrm{cmm}$ other investigations like renal and liver function tests, serum electrolytes, coagulation profile, blood sugar levels were within normal limit. Her beta-HCG was $6824 \mathrm{mIU} / \mathrm{ml}$ corresponding to that of 5-6 weeks of gestation and was not significantly raised.

Patient was taken inside OT with Consent for surgery, High risk consent explaining the poor prognosis of intrauterine pregnancy obtained from both the patient and her spouse. Peripheral venous cannulation of $20 \mathrm{G}$ and $18 \mathrm{G}$ were secured. Compressive stockings for thromboembolic prophylaxis and Aspiration prophylaxis was given. Blood and Blood products were reserved. Pulse oximetry, electrocardiogram, non-invasive blood pressure, capnography was used for intra- operative monitoring.

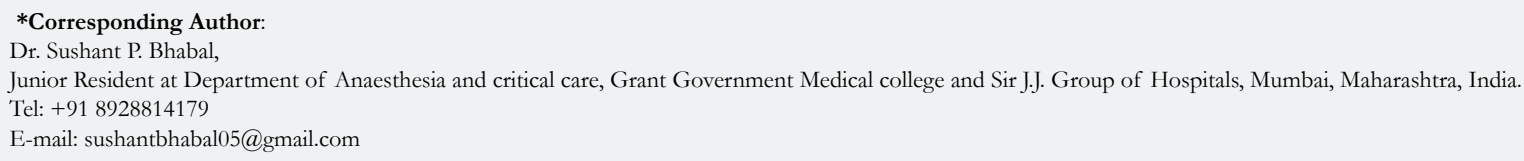


To minimise the duration of exposure to anaesthesia; induction was done only after laparoscopy set ups and arrangements. We preoxygenated the patient for $4 \mathrm{~min}$. She was administered Inj. Glycopyrrolate $0.004 \mathrm{mg} / \mathrm{kg}$, Inj. Ondansetron $0.08 \mathrm{mg} / \mathrm{kg}$ was given as premedication, Inj. Propofol $2 \mathrm{mg} / \mathrm{kg}$ was given for induction, Inj. Atracurium was used as muscle relaxant. Patient was intubated with $7.5 \mathrm{~mm}$ oral cuffed endotracheal tube. Sevoflurane was used as a maintenance agent, we used Oxygen: air in a ratio of 50:50. Inj. Paracetamol $1 \mathrm{gm}$ iv infusion was administered for analgesia. Intraabdominal pressure was maintained between $8-10 \mathrm{mmHg}$ for adequate venous return and to avoid hypercarbia. After completion of procedure reversal was given and the patient was extubated.

\section{Discussion}

Heterotopic pregnancy is the presence of intrauterine pregnancies co-existing with an ectopic pregnancy [3]. The fallopian tube being the most common site [4]. The occurrence of a heterotopic pregnancy is rare in natural conception cycles with an incidence of $0.08 \%$, but incidence increases to as high as $1-2.9 \%$ with assisted reproductive techniques [5]. Out of 217 cases of heterotopic pregnancies reported in literature, $90.78 \%$ were managed surgically which consists of salpingectomy via laparotomy or laparoscopy depending on patient's heiodynamic conditions, in which survival rate for the intra-uterine foetus was found $64.4 \%$ and miscarriage can occur in about $35.6 \%$ [6].

The risk factors for heterotopic pregnancy includes history of infertility, intrauterine device or hormonal contraception, pelvic inflammatory disease (PID), previous surgery or previous ectopic pregnancies, ovulation induction and assisted reproductive technologies (ART [7]).

Patients can come with symptoms like abdominal pain, mass, peritoneal irritation although in some cases either hypovolemic shock or totally asymptomatic. Early symptoms mimics acute appendicitis, ovarian cyst rupture, or ovarian torsion making it difficult to diagnose [8]. Approximately $70 \%$ of heterotopic pregnancies are diagnosed between 5-8 weeks, 20\% are diagnosed between weeks 9 and 10 , and the remaining $10 \%$ are diagnosed at or beyond the 11 th week [9].

Our primary concern in this case was surgery in the first trimester of pregnancy. The basic aim is avoidance of any drug or technique, which can interfere with proper embryological development. As such maintaining oxygenation, euvolemia, normocapnia and haemodynamic stability are the main objectives for the administration of anaesthesia [10].

We preferred General anaesthesia although regional anaesthesia provides less foetal drug exposure, better airway security, lesser blood loss but it causes hypotension resulting from sympathetic nerve blockade, which decreases uterine blood flow and perfusion to the foetus [11].

According to studies published the laparoscopic surgery offers many advantages over conventional open procedures; these include smaller incision, minimal blood loss, decreased post-operative pain, decreased requirement of opioids and analgesics, decreased foetal depression, early ambulation and shorter hospital stay However one has to be cautious regarding the risks as well which includes accidental trocar injury, pneumoperitoneum with $\mathrm{CO}_{2}$ causing systemic carbon dioxide absorption, maternal hypercarbia resulting into foetal respiratory acidosis, venous gas embolism [12].

Following precautions were taken considering maternal safety:

Aspiration prophylaxis: As there is an increased the risk of regurgitation and aspiration due to decreased lower oesophageal sphincter tone [13]. Non particulate antacids and H2-Receptor antagonist were used.

Thromboprophylaxis: The risk of thrombosis is higher as pregnancy is hypercoagulable state also due to immobilisation during the peri-operative period [14]. We used leg compression stockings to prevent deep vein thrombosis.

Maintaining Blood pressure: Prolong maternal hypoxaemia causes uteroplacental vasoconstriction which decreased uteroplacental perfusion that can result in foetal hypoxaemia, acidosis, and death [15].

Maintaining normocapnia: Hypercapnia can cause uterine artery vasoconstriction and reduced uterine blood flow [16]. Thus, intra-abdominal insufflation pressure was maintained between 8-10 $\mathrm{mmHg}$.

\section{Teratogenicity anaesthetic agents}

We avoided the use of Nitrous oxide (N2O) as it inhibits methionine synthetase which is necessary for DNA synthesis. Teratogenic effects are shown in animal studies after giving high concentrations for long periods however such high doses are not required in practice [17].

We avoided the use of Benzodiazepine as it has been associated with cleft palate and cardiac anomalies. However, it is usually recommended to avoid benzodiazepine use throughout gestation and most especially during the first trimester [18].

There are very few case reports regarding the outcome of foetus in such cases who underwent general anaesthesia and Laparoscopic surgery in a first trimester of pregnancy.

In Literature there are very few cases that have been reported and not many focuses on anaesthesia considerations and its management. We kept Follow up of our patient confirming a successful outcome hence we recommend a multidisciplinary team approach between an Anaesthesiologist, Gynaecologist and considering necessary precautionary measures for continuation of an ongoing pregnancy while excision of Ectopic pregnancy.

\section{Conclusion}

It is challenging for an anaesthesiologist in particular case as we are dealing with not one but two patients at the same time. Though maternal safety is our primary concern; but real success lies in conserving an ongoing pregnancy and achieve a better foetal outcome. 


\section{References}

[1]. Gray W, Rumack CM, Wilson SR, Charboneau JW. Diagnostic ultrasound. New York: Mosby; 1998; 999.

[2]. Glassner MJ, Aron E, Eskin BA. Ovulation induction with clomiphene and the rise in heterotopicpregnancies: A report of two cases. J Reprod Med. 1990;35:175-8. PMID: 2406440.

[3]. Govindarajan MJ, Rajan R. Heterotopic pregnancy in natural conception. J Hum Reprod Sci. 2008;1(1):37-38. PMID: 19562064.

[4]. Devoe RW, Pratt JH. Simultaneous intrauterine and extrauterine pregnancy. Am J Obstet Gynecol.1948;56:1119-26. PMID: 18893768.

[5]. Berger MJ, Taymor ML. Simultaneous intrauterine and tubal pregnancies following ovulationinduction. Am J Obstet Gynecol. 1972;113:812-3. PMID: 4635717.

[6]. Diallo D, Aubard Y, Piver P, Baudet JH. Grossessehétérotopique: à propos de cinq cas et revue dela littérature. J GynecolObstetBiol Reproduction. 2000;29(2):131-14.

[7]. Reece EA, Petrie RH, Sirmans MF, Finster M, Todd WD. Combined intrauterine and extrauterinegestations: a review. Am J Obstet Gynecol. 1983;146:323-30. PMID: 6344638.

[8]. Chen $\mathrm{KH}$, Chen LR. Rupturing heterotopic pregnancy mimicking acute appendicitis. Taiwan J ObstetGynecol. 2014;53:401-3. PMID: 25286800.

[9]. Tal J, Haddad S, Gordon N, Timor-Tritsch I. Heterotopic pregnancy after ovulation induction andassisted reproductive technologies: a literature review from 1971 to 1993. FertilSteril. 1996;66:1-12. PMID: 8752602.
[10]. Chang J, Streitman D. Physiologic adaptations to pregnancy. NeurolClin. 2012;30:781-9. PMID: 22840789.

[11]. Bajwa SJ, Bajwa SK. Anaesthetic challenges and management during pregnancy: Strategiesrevisited. Anesth Essays Res. 2013;7(2):160-167. PMID: 25885826.

[12]. Upadya M, Saneesh P J. Anaesthesia for non-obstetric surgery during pregnancy. Indian J Anaesth2016;60:234-41.

[13]. Wong CA, McCarthy RJ, Fitzgerald PC, Raikoff K, Avram MJ. Gastric emptying of water in obesepregnant women at term. AnesthAnalg 2007;105:751-5.

[14]. Guyatt GH, Akl EA, Crowther M, Gutterman DD, Schuünemann HJ. Executive Summary: Antithrombotic Therapy and Prevention of Thrombosis, 9th Ed: American College of Chest Physicians Evidence-Based Clinical Practice Guidelines. Chest. 2012;141(2 Suppl):7S-47S. PMID: 22315257.

[15]. Dilts PV, Brinkman CR, Kirschbaum TH, Assali NS. Uterine and systemic hemodynamicinterrelationships and their response to hypoxia. Am J Obstet Gynecol. 1969; 103: 138-157. PMID: 5761772.

[16]. Walker AM, Oakes GK, Ehrenkranz R, McLaughlin M, Chez RA. Effects of hypercapnia onuterine and umbilical circulations in conscious pregnant sheep. J Appl Physiol. 1976; 41: 727-733. PMID: 993146.

[17]. Fujinaga M, Baden JM. Methionine prevents nitrous oxide-induced teratogenicity in rat embryosgrown in culture. Anesthesiology. 1994;81:184-9. PMID: 8042787.

[18]. Safra MJ, Oakley GP. Association between cleft lip with or without cleft palate and prenatalexposure to diazepam. Lancet. 1975;2:478-80. PMID: 51287. 